\title{
Análisis del valor y evaluación multicriterio en la gestión del Patrimonio Histórico
}

\section{Pedro Pérez Quesada}

Becario de Investigación. Grupo de Investigación SIGPAR

Dpto. Prehistoria y Arqueología Universidad de Sevilla
Zeuxis, uno de los más famosos pintores de la Grecia Antigua, era célebre por el realismo de sus pinturas y su habilidad en el tratamiento de la figura femenina. De él se conoce un episodio con los crotoniatas que tuvo cierta notoriedad en la literatura de la Antigüedad y que conviene al caso que presentamos. Se dice, nos lo cuenta Cicerón en De inuentionel, que en cierta ocasión los habitantes de Crotona contrataron a Zeuxis de Heraclea para enriquecer con pinturas el Templo de Juno. Zeuxis, que pasaba por ser el mejor de todos los pintores, les dijo que quería reproducir la figura de Helena como ideal perfecto de belleza femenina y por ello preguntó inmediatamente cuáles eran las más bellas jóvenes que allí vivían. Condujeron al pintor directamente al gimnasio y le mostraron muchos jóvenes dotados de gran belleza. Y mientras Zeuxis los admiraba le dijeron: "En casa están las hermanas de estos jóvenes; por ellos puedes hacerte una idea de su belleza". "Por favor", les contestó, "enviadme a las más bellas de esas muchachas mientras pinto lo que os he prometido, para que la verdadera belleza de estos modelos vivos pase a un cuadro mudo". Entonces los ciudadanos de Crotona, tras una deliberación pública, reunieron a las jóvenes en un mismo lugar y permitieron al pintor elegir la que prefiriese. Él, sin embargo, eligió cinco jóvenes cuyos nombres transmitirían después muchos poetas porque les dio su aprobación quien, en lo referente a belleza, tenía sin duda el juicio más seguro. En efecto, creía que no podría encontrar en un solo cuerpo todas las cualidades que buscaba para representar la belleza ideal: la naturaleza, al decir de Cicerón, como si temiera carecer de dones para conceder a otras personas si los otorgara todos a una, ofrece a cada una diferentes cualidades a la vez que añade algún defecto.

Sacar de esta historia una conclusión corresponde a cada uno de sus lectores, sin embargo, al caso que nos ocupa interesa fundamentalmente el procedimiento de la elección, y las cualidades de la belleza. Estos dos aspectos, salvando las diferencias, tienen su práctica diaria en la gestión del Patrimonio Histórico. Cada una de las actuaciones sobre el Patrimo- nio lleva implícita una decisión, una elección entre diversas alternativas, incluso la "no acción" (la solución trivial), con un cierto grado de incertidumbre. Esta incertidumbre supone riesgos y beneficios para el patrimonio mismo, que necesitan ser sopesados desde las diferentes perspectivas o criterios de la decisión: su interés social, económico, político, etc.; sus posibilidades y necesidades de conservación; sus riesgos materiales y restauraciones; sus tasaciones de mercado, expropiadoras, etc.; sus adaptaciones a usos turísticos, educativos, editoriales, expositivos... ; en fin, un sinnúmero de perspectivas que tal como se han mencionado pierden todo su grado de concreción. Son, como se suele decir, subjetivas, aunque no por ello negativas; tan sólo han de definirse, objetivarse para el problema de decisión dado. La situación de compromiso está en definir los márgenes de cada concepto ya que escapar de las preferencias individuales no es posible.

El segundo punto de interés en la narración se refería a las cualidades de la belleza, a sus atributos. Como cualquier otro objeto de estudio, todo bien histórico posee unas cualidades que lo diferencian y le dan su peculiaridad, manifestándose con distinta valía según la función que pretendamos que cumpla. Además, para cada función que deba cumplir el objeto, en su valoración se tendrán que considerar atributos y criterios diferentes.

Esta distinción entre atributos y criterios no es sino la estructura lógica de todo proceso de valoración y decisión. Como en los sistemas de comunicación², en la gestión y estudio del Patrimonio se puede establecer un sistema de signos que permitan identificar y relacionar los conceptos; los significados de los signos no son absolutos, sino que dependen del contexto en que se encuentren. Igualmente en cada problema de decisión se redefinen los significados de criterios y atributos. Lo único que no cambia es la estructura jerárquica de los conceptos o signos, no sus significados que sí cambian. Y acaso tampoco cambian, al menos rápidamente, aquellos valores últimos que dan sentido a lo patrimonial (bienestar 
La concepción de los objetos del legado histórico como bienes significa que de alguna manera son objeto de valoración de acuerdo con los criterios de valor universal. La racionalización de estas valoraciones puede realizarse mediante el Análisis del Valor y la Evaluación Multicriterio de acuerdo con fines o usos patrimoniales más específicos.

social, trabajo, delectación...) y que por su versatilidad pueden adaptarse a diferentes contextos.

Una vez introducidos, con estas ideas básicas podremos observar, siquiera fugazmente, cómo se entiende el concepto de valor en la gestión y normativa patrimonial, cómo ha sido concebido por otras ciencias sociales, especialmente desde el campo de la economía, y cómo entiendo que puede ser definido y utilizado en la práctica para la evaluación y toma de decisiones de cara a una gestión estratégica del Patrimonio Histórico.

\section{LOS VALORES DEL PATRIMONIO HISTÓRICO}

La asignación de valores a los elementos materiales del pasado se puede rastrear incluso en las formaciones sociales más elementales; los mitos, leyendas, amuletos o curiosidades del pasado se han relacionado con la regulación de relaciones políticas y sociales ${ }^{3}$. En la Antigüedad el interés por el pasado se acrecentaría y haría más sistemático; se dice que la colección de artefactos e inscripciones de la princesa asiria Ben-Shalti-Nannar se podría considerar el primer museo de antigüedades conocido4; en China el estudio del pasado fue muy valorado en tiempos de Confucio (55 I-479 a.C.) como guía moral de comportamiento y desempeñó una función muy poderosa dentro del proceso de unificación de la vida política y cultural. Sin embargo, al igual que en las civilizaciones clásicas del Mediterráneo, la atención sobre los objetos materiales tenía un carácter de curiosidad o reliquia familiar³. Será con el Renacimiento italiano cuando comience una actitud favorecedora de la conservación de bienes históricos. El mecenazgo de las artes y el interés por la antigüedad clásica como justificación de un pasado esplendoroso potenció esta actitud conservadora; de hecho, en una fecha tan temprana como 1462, el papa Pío II promulgó una ley de preservación de las edificaciones antiguas de los estados papales y, en I47I, Sixto IV prohibió la exportación de bloques de piedra o estatuas de sus dominios ${ }^{5}$.
En España las primeras iniciativas, medidas o normas en las que late la preocupación por la conservación de lo que hoy llamamos Patrimonio Histórico surgirá con la llustración: la creación de la Academia de Nobles Artes en 1752 (Bellas Artes de San Fernando desde 1773), la prohibición de exportación de pinturas y objetos artísticos antiguos por Real Orden de 16 de octubre de 1779, la encomendación a la Academia de la Historia de recoger y conservar los monumentos que se descubriesen en el reino por Real Cédula de 6 de junio de I803...; El siglo XIX continuará las tesis conservacionistas y reconocerá la importancia de los bienes histórico-artísticos: creación del Museo del Prado el 26 de diciembre de |8|4, creación de las Comisiones de Monumentos Históricos y Artísticos, una en cada provincia y otra central en 1844, inauguración del Museo Arqueológico el 20 de marzo de 1867, prohibición de transmisión de obras de arte de la Iglesia sin informe previo de la Real Academia por Real Orden de 10 de abril de 1866 y por último un Decreto de 16 de diciembre de 1873, en el que se ordena a los Ayuntamientos y Diputaciones que vigilen los monumentos a efectos de evitar la destrucción de edificios públicos con méritos artísticos e históricos. Pese a estas disposiciones y normativas el siglo XIX resultó realmente lesivo: la invasión napoleónica, la política desamortizadora, las reformas urbanas (ensanches y cuadriculados especialmente) y la desidia de los gobernantes en casos sobresalientes dan una medida del valor real asignado a estos bienes. Sobre este último aspecto los ejemplos más destacados se refieren a bienes muebles: es de resaltar la falta de respuesta de las autoridades españolas de la época al manifiesto deseo de Wellington de restituir la importante colección de pinturas que José Bonaparte pretendía llevarse a Francia y que fue recuperado por el ejército hispano-británico en la batalla de Vitoria de 18।3; la colección constituye hoy el componente básico del Museo Wellington en la Aspley House de Londres. Igualmente ejemplares son las subastas de la colección del Marqués de Salamanca en 1867 y 1875 en París, en las que se vendieron 233 y 118 cuadros de pintura respectivamente 6 . 
La visión monumentalista heredada deI XIX, desde el Catálogo Monumental y Artístico (R.D. de I de junio de 1900), pasando por las distintas normativas y disposiciones nacionales e internacionales dictadas hasta nuestros días, será la más acentuada en nuestra centuria y aún hoy es prioritaria. En la actualidad los criterios justificativos de la protección del Patrimonio están basados enormemente en las recomendaciones internacionales. Los principios inspiradores suelen hacer referencia a valores históricos, artísticos, científicos o técnicos que proporcionen aportaciones a la cultura mundial. Especial importancia tienen en esta concepción mundial del Patrimonio las Recomendaciones Internacionales inmediatas a la Segunda Guerra Mundial y la constitución de la UNESCO en el seno de las Naciones Unidas el 16 de noviembre de 1945, cuyo propósito y funciones, definidos en Conferencias Generales, queda articulado asi?:

\begin{abstract}
"La Organización se propone contribuir a la paz y a la seguridad estrechando, mediante la educación, la ciencia y la cultura, la colaboración entre las naciones, a fin de asegurar el respeto universal a la justicia, a la ley, a los derechos humanos y a las libertades fundamentales que sin distinción de raza, sexo, idioma o religión, la Carta de las Naciones Unidas reconoce a todos los pueblos del mundo."
\end{abstract}

(UNESCO.

Documento Constitutivo actualizado, 1994)

Resulta curioso cómo esta finalidad para la paz ha de protegerse en tiempos de guerra: el 14 de mayo de 1954 se firma el Convenio para la Protección de los Bienes Culturales en caso de conflicto armado, firmado en La Haya e inspirado en precedentes como las Convenciones de La Haya de 1889 y de 1907 y en el Pacto de Washington de 19358.

Es en las primeras Recomendaciones de la posguerra cuando se fijan las concepciones actuales de $\mathrm{Pa}$ trimonio Histórico y Bienes culturales, matizadas por declaraciones posteriores. En ellas, al igual que en nuestra Ley de Patrimonio Histórico la referencia a conceptos de una alta abstracción, los valores, han servido para estructurar un lenguaje con márgenes de comprensión muy ambiguos. En cierta manera podemos reconocer aquí que los fundamentos de la conservación del Patrimonio son esencialmente morales ${ }^{9}$ y están establecidos desde los poderes fácticos (la intelectualidad, los mass media, la política...). Pero es la concienciación creciente de buena parte de la sociedad en esta nueva creencia lo que le ha dado su justificación práctica. Y esto no nos ha de sorprender: por ejemplo, la creencia colectiva en el dinero como medio de cambio tiene su fundamento en la solidez de los poderes fácticos y en la confianza social. Vistas así las cosas, la afirmación de que el Patrimonio tiene un valor intrínseco no se sostiene y por eso mismo resulta paradójico que se insista en dar la espalda a esta realidad: el Patrimonio sin sociedad que lo reconozca no sirve, en un sistema democrático, para nada que no sea el interés particular del investigador y su exclusivo beneficio. Entendida la Cultura como un nuevo dogma, las recomendaciones internacionales insistirán en este aspecto social del Patrimonio que nuestra legislación resume asílo:

\begin{abstract}
"su valor lo proporciona la estima que, como elemento de identidad cultural, merece a la sensibilidad de los ciudadanos. Porque los bienes que lo integran se han convertido en patrimoniales debido exclusivamente a la acción social que cumplen, directamente derivada del aprecio con que los mismos ciudadanos los han ido revalorizando."
\end{abstract}

(Ley 16/1985, de 25 de junio, del PHE)

Pese a las ambigüedades, se han ido configurando Listas, Catálogos e Inventarios con la finalidad última de servir a aquellos valores intangibles, lo que ha obligado a definir conceptos y criterios de diferenciación más concretos. La Lista del Patrimonio Mundial, configurada en el seno de la UNESCO, ha servido de referencia máxima; los criterios establecidos por el Comité del Patrimonio Mundial"', elegido en Asamblea General, sirven de base para la inscripción de bienes. Se consideran dos grandes criterios u órdenes, Patrimonio Natural y Patrimonio Cultural, y se trata de evaluar el mérito de las propiedades intrínsecas del bien sin la estima de cualquier otra consideración (incluyendo necesidades técnicas); el punto de partida son las listas propuestas por los Estados miembros, que se acompañan de toda la documentación necesaria para la evaluación de los bienes en función de su valor universal. Mapas, diapositivas, análisis breve de referencias en la literatura mundial, conjuntamente con una literatura comprensiva, se considera información relevante para justificar su valor universal. Otros criterios más concretos sirven para la comparación con bienes de tipo similar: Monumentos, Conjuntos (de tres tipos: ciudades deshabitadas, ciudades históricas y ciudades del siglo XX) y Lugares (distinguiendo: paisajes diseñados y paisajes por evolución - con subtipos: fósil, continuo y cultural). Sobre estos criterios se consideran unas cualidades $\mathrm{o}$ atributos que proporcionan las características imprescindibles para ser incluidos en la Lista y que cada bien puede poseer en mayor o menor medida. Entre los atributos se tienen en cuenta aspectos relacionados con su importancia universal, análisis comparativos con otros lugares, la gestión actual y previsible del bien, su capacidad de carga y otros aspectos indicativos del grado de conservación, en prevención de la afluencia de público que tal denominación conlleva. Es importante resaltar que la inclusión en la Lista está sujeta a revisiones que pueden implicar la exclusión de bienes mal gestionados ${ }^{12}$.

Una estructura jerárquica parecida se encuentra en nuestra legislación nacional y autonómica (al menos en Andalucía ${ }^{13}$ ). En su Preámbulo la Ley de Patrimonio Histórico Español deja clara su vinculación al valor universal del bien: 
"La Ley establece distintos niveles de protección que corresponden a diferentes categorías legales. La más genérica y que da nombre a la propia Ley es la de Patrimonio Histórico Español, constituido éste por todos aquellos bienes de valor histórico, artístico, científico o técnico que conforman la aportación de España a la cultura universal. En torno a ese concepto se estructuran las medidas esenciales de la Ley y se precisan las técnicas de intervención...”.

(Ley 16/1985, de 25 de junio, del PHE)

Los bienes más singulares, según estos criterios universalistas ${ }^{14}$, son incluidos en el Registro General de Bienes de Interés Cultural o en el Inventario General, dependientes de la Administración del Estado, o en el Catalogo General de Patrimonio Histórico Andaluz (inscripción genérica o específica y anotaciones preventivas) dependiente de la Comunidad Autónoma. Criterios más concretos son: bienes muebles e inmuebles; Monumento, Conjunto Histórico, Jardín Histórico, Sitio Histórico, Zona Arqueológica y Lugar de Interés Etnológico (éste último es particular de la comunidad andaluza); Patrimonio Arqueológico, Etnográfico, Bibliográfico, Documental; y de los Archivos, Bibliotecas y Museos. Los atributos concretan las cualidades que puede poseer un bien y que lo caracterizan. Sólo en ocasiones, de oficio o a instancias del titular del bien, se plantea la revisión de las inscripciones hacia niveles inferiores.

Lo sorprendente de toda la estructura legal es que es un edificio cimentado sobre la indefinición de funciones patrimoniales $\mathrm{o}$ al menos están desarrolladas escasamente; aún cuando en los registros de bienes se incluye normalmente un apartado dedicado a usos, estos normalmente sólo reflejan el uso actual de cada bien y sin una relación con los demás bienes y circunstancias de su entorno social que permitan la proposición de otros usos potenciales. El esfuerzo de relacionar bienes en su contexto espacio-temporal y socioeconómico es necesario si lo que se pretende es incrementar el valor del Patrimonio; de cajón es decir que primero habrá que estimar el valor actual. La tutela que corresponde a la autoridad pública no puede ser entendida como una mera acción administrativa y resolutiva de expedientes individuales, por más necesarios que sean; como señalaba el catedrático Pedro Dorado:

"Solamente su carácter de función tutelar, es lo que justifica la existencia de la autoridad y de la ley y lo que las mantiene. Es cierto que una y otra no suelen perseguir, como se ha dicho, más que la utilidad de los dominadores; pero también lo es que con ellas se logra, aún sin pretenderlo, la utilidad de los dominados. [...] La autoridad pública no tiene otra razón de ser que la autoridad paterna, y que su ejercicio, si de algún modo se justifica, es por los servicios útiles, o sea tutelares, que puede prestar a los sometidos a ella. Cuando encuentre necesidades humanas no satisfechas, y ella disponga de medios para esa satisfacción, está obligada a ponerlos, y si no los pone, falta a su

cometido, al motivo que la mantiene en pie"

Pedro Dorado.

Valor Social de Leyes y Autoridades, $1923^{15}$ )

No deja de ser representativo que los bienes eclesiásticos constituyan la mayor parte de los bienes conservados en España (más de 60.000 monumentos según estimaciones de 198416), lo cual, aparte de la sacralización social de los bienes -algo muy relacionado con lo que venimos viendo-, se debe principalmente a la continuidad de usos que han recibido. La Comisión Mixta, creada a partir del "Acuerdo entre el Estado Español y la Santa Sede sobre Enseñanza y Asuntos Religiosos"17, dio a la luz un "Documento relativo al marco jurídico de actuación mixta Iglesia-Estado sobre Patrimonio Histórico Artístico"vi con fecha 30 de octubre de 1980, en el que se desarrollaron los criterios básicos al respecto; se establecía un claro reconocimiento de prioridades en el tratamiento de los bienes eclesiásticos: uso preferente de los actos litúrgicos y religiosos, coordinación de este uso con el estudio científico y artístico de los bienes en segundo lugar y, por último, regulación de la visita, conocimiento y contemplación de estos bienes de la forma más amplia posible. A esta jerarquía de criterios se añadía la necesidad del inventario de todos bienes muebles e inmuebles.

El orden de preferencias de la Iglesia puede ser discutido o aceptado y la determinación de sus criterios rechazada o no, pero lo que interesa resaltar es, primero, que se explicitan unos criterios de actuación en función de unos usos claramente diferentes entre sí y, segundo, que se establece un orden entre ellos. Así se estructura un sistema que permite valorar los bienes en función de usos diferentes.

No abogo aquí en contra de la recurrencia continua a valores universales, lo que señalo es la insuficiencia de estas justificaciones sin una reflexión práctica sobre los usos del Patrimonio Histórico. De hecho, la realización de inventarios y otros mecanismos de registro exhaustivo sirven y son utilizados en la definición de usos, siendo instrumentos imprescindibles para la evaluación. Su necesidad se muestra claramente en la gestión urbanística, donde las decisiones que afectan al Patrimonio Histórico, cuando se realizan o proyectan, han de soportar el estrés provocado por las particularidades económicas y funcionales de la ciudad (terciarización, habitabilidad, tráfico, aparcamientos, etc.). Se observa así en Sevilla:

"El encuadre de los distintos aspectos y conflictos urbanísticos que afectan al desarrollo y evolución de las ciudades históricas ha de realizarse siempre buscando un equilibrio dentro de una doble vertiente: las de transformaciones de sustitución/reforma interior y la de rehabilitación/conservación de sus valores patrimoniales"

(Sevilla. Avance del Plan Especial de Protección. 1995$)^{18}$ 
A la complejidad urbanística hay que añadir las inconveniencias derivadas de la concurrencia de ordenamientos jurídicos (Leyes del suelo, Leyes del Patrimonio histórico, legislación medioambiental...), de divergentes competencias públicas (estatales, autonómicas y municipales) y de los derechos, obligaciones e intereses privados. Siendo en la ciudad y su territorio municipal donde se aplican finalmente todas las disposiciones normativas y de gestión, no deja de ser relevante que en ellas se plantee la necesidad de establecer inventarios patrimoniales para su conocimiento, control y ejecución de acciones:

"La documentación y conservación del Conjunto Histórico Declarado pasa necesariamente por un conocimiento completo de éste, en base al cual tomar decisiones y prever estrategias"

(Sevilla. Avance del Plan Especial de Protección. 1995)

La cuestión principal que quiero plantear está en definir qué es el valor de cara a la toma de decisiones; para ello trataré de llegar a su definición a través de un recorrido por las teorías económicas del valor, por ser en este campo donde más se ha incidido y donde se ofrecen mecanismos operativos de fiabilidad más contrastada.

\section{EL CONCEPTO DE VALOR EN ECONOMÍA}

Hay que retrotraerse a la escolástica aristotélica para encontrar las fuentes principales del concepto de valor. Las interpretaciones escolásticas del pensamiento griego antiguo, introducido en Europa por árabes y bizantinos desde 1250, serían fundamentales en este sentido y tendrían una fuerte influencia posterior. Las aportaciones más importantes fueron las de Tomás de Aquino y Alberto Magno: el primero establecía el origen del valor de las cosas en la utilidad, idea que sería asumida y transmitida por los dominicos, el segundo lo atribuía al trabajo necesario para producirlas, influyendo especialmente en los franciscanos. El pensamiento que los escolásticos contribuyeron a desarrollar tuvo como referencia la idea de que la riqueza, el valor económico, no es condenable19.

La epistemología del valor, la definición de sus causas finales, se convertiría en adelante en un aspecto fundamental de la política económica de los nacientes Estados Modernos. A partir de aquellas ideas bajomedievales el mercantilismo encontró en la riqueza material su ley motora y en la tierra hallarían los fisiócratas su fundamento. Importantes figuras del mercantilismo, como J. Hales, siguiendo las tesis franciscanas, destacarían el trabajo como causa prioritaria de la riqueza de un país y señalarían el pleno empleo como el objetivo fundamental para alcanzar un mayor poderío económico.
El papel prioritario del trabajo fue heredado en los planteamientos de los "teóricos clásicos del valor" (A. Smith20, D. Ricardo21 y K. Marx ${ }^{22}$ ) -1770/1870-, con un apartamiento sucesivo de los términos de escasez y utilidad como causas del valor (la postura más extrema la establecería Marx, al convertir al trabajo en el único origen del valor, y a su vez el trabajo entendido exclusivamente como fuerza). Al entender que el concepto de utilidad está basado en las apreciaciones personales los teóricos clásicos lo descartaron en su pretensión de plantear una teoría objetiva. Por esta razón las teorías del valor clásicas están basadas en la oferta -su elemento principal es el coste ${ }^{23}$.

Aunque la línea dominica, centrada en la utilidad, fue heredada por teóricos como Benthan( I 780) en su propuesta de cálculo felicífico ${ }^{24}$, lo cierto es que hasta la década de 1870 no se reincorporarán las causas subjetivas del valor de la mano de los "teóricos de la utilidad marginal". Las causas del valor se situarán en las futuras necesidades y objetivos del sujeto que demanda. El concepto de utilidad marginal permitía introducir la escasez en combinación con la utilidad: la utilidad decrece cuando la cantidad aumenta. Se puede hallar entre los marginalistas dos corrientes, una más filosófica, en la que destacan Jevons y Menger ${ }^{25}$, y otra que establece en bases matemáticas el sustento de su teoría y representada por Walras 26 , y Pareto 27 como figuras destacadas. Menger fundamenta la teoría de la utilidad en el valor subjetivo, en la significación que para cada individuo tienen ciertos bienes; los bienes pueden ser actividades o cosas materiales, pero siempre útiles:

\section{"Para que una cosa pueda convertirse en bien, o dicho con otras palabras, para que una cosa alcance la cualidad de bien, deben confluir las cuatro condiciones siguientes:}

\section{Una necesidad humana.}

2. Que la cosa tenga tales cualidades que la capaciten para mantener una relación o conexión causal con la satisfacción de dicha necesidad.

\section{Conocimiento por parte del hombre de esa} relación causal.

4. Poder de disposición sobre la cosa, de tal modo que pueda ser utilizada de hecho para la satisfacción de la mencionada necesidad."

(Menger, C., Principios de Economía Política, 1899)

La corriente matemática del marginalismo se centró más en los postulados de funciones de utilidad social y de equilibrio general, aunque sin considerar la noción de criterios distintos y más o menos contradictorios. Las funciones de utilidad trataban de expresar de una forma global la elección del consumidor o del productor ante alternativas diferentes y a menudo en conflicto; Pareto mostró para estos casos que no todos los agentes podían obtener su satisfacción máxima al mismo tiempo y que 
existe un óptimo (optimalidad paretiana) en el que ninguno de los agentes puede beneficiarse sin perjudicar a otro28. La labor de clarificación y refinamiento del concepto de optimalidad y la discusión de sus implicaciones daría origen a la Economía del Bienestar.

El primer intento de superar el criterio de Pareto lo efectuarían los teóricos de la Nueva Economía del Bienestar, sin embargo, su insistencia en no introducir juicios de valor explícitos llevaría a una maraña conceptual y su trabajo se saldó con un fracaso ${ }^{29}$. Correspondería a A. Bergson 30 la introducción del concepto de Función de Bienestar Social basado en las preferencias sociales mediante la asignación de índices de utilidad.

En otro sentido, la simbiosis de ideas de clásicos y marginalistas junto con aportaciones centradas en el capital (entendido como medios de que se dispone para la producción) y el interés (beneficio producido por el capital) dirigieron otras investigaciones sobre el valor hasta la Segunda Guerra Mundial y tienen su continuidad en la actualidad. Sin embargo, a partir de la guerra se producen cambios en las concepciones económicas que se traducen en metodologías prácticas de valuación y toma de decisiones. Son estas metodologías las que, en mi opinión, pueden ser aplicadas a los procesos de valuación del Patrimonio Histórico con las adaptaciones previas imprescindibles: El Análisis del Valor y los métodos de Decisión Multicriterio.

\section{Análisis del Valor}

El análisis del valor se puede concebir como una metodología de organización y gestión. Su impulso se debió a las fuertes subidas de precios en las materias primas durante la posguerra, lo que obligó a un mayor control económico de éstas y sus proveedores y a la búsqueda de elementos sustitutivos alternativos. En concreto su origen se encuentra en el estudio que la General Electric encargó a L.D. Miles sobre las experiencias de la guerra y para el desarrollo de un método que con planificación, y no por azar, designase las alternativas que cumplían mejor las especificaciones deseadas; Miles estructuró así una serie de técnicas en lo que llamó Value Analysis $(1947)^{31}$. Para Miles ${ }^{32}$ es fundamental la distinción clásica del concepto de valor en varias categorías que define así:

- Valor de uso. Propiedades y cualidades que sirven para una aplicación, trabajo o servicio. En términos cuantitativos entiende que es el (costo) mínimo para conseguir la ejecución precisa de una función.

- Valor estimado. Propiedades, características o atractivos que excitan en nosotros el deseo de poseerlo. En términos cuantitativos entiende que es el (costo) mínimo para obtener la presentación, atractivo y características que la clientela desea.
- Valor de coste. La suma de mano de obra, materiales y demás costos necesarios en su fabricación.

- Valor de cambio. Propiedad o cualidades que nos permiten cambiarlo por otro producto que necesitamos.

Según Miles, para los estudios del valor son las dos primeras categorías las más utilizadas: los valores de uso requieren funciones que hagan que el producto sirva para un fin determinado, mientras que los valores de estimación necesitan (o más bien sirven para) que el producto se venda.

El análisis se centra en todos los procesos y productos secundarios que conducen al producto demandado; los objetivos son reducir costos y mejorar la satisfacción. El método analiza funciones y define las prestaciones y funcionamiento que demanda el usuario. Para ello se aconsejan una serie de medidas de acción, como son: evitar generalidades, identificar los costos existentes, usar la facultad de creación (idear, crear y mejorar apoyándose en sesiones de Brainstorming o tormenta de ideas ${ }^{33}$ ), consultar y colaborar con los especialistas y proveedores, concentrar esfuerzos en los principales problemas detectados o cuellos de botella, evitar la inclinación al "hagámoslo nosotros" sin estudiar productos existentes o alternativos...

La metodología de análisis del valor estará muy ligada al concepto de calidad y a la organización del trabajo. Durante los años cincuenta, bajo el dominio de la filosofía tayloriana de organización científica del trabajo, la calidad se basará en el estudio del producto acabado o semiacabado a través de inspecciones. A partir de los sesenta el lema es "la calidad no se controla, se fabrica" (Built in Quality o calidad incorporada); frente a la inspección esporádica el control continuo. En los ochenta se produce la irrupción en los mercados mundiales de los productos japoneses de alta calidad basados en los conceptos de Gestión Total de Calidad (Total Quality Control), inspirados en las técnicas de análisis del valor estadounidenses pero desarrolladas a gran escala en Japón tras las crisis energética de 1973. Sus principios básicos son 34 :

- La calidad no es responsabilidad de un departamento específico, sino de toda la empresa.

- La meta es cero defectos.

- La prevención frente a la solución de problemas.

- La prevención se hace lo antes posible para evitar la acumulación de costos.

Lo más característico de la nueva organización empresarial es la conformación de los Círculos de Calidad; éstos son grupos de trabajadores unidos "voluntariamente" en torno al objetivo común de mejorar el proceso de producción concreto que les afecta y de la calidad generada en el conjunto de la empresa. Se trata de un nuevo modelo de gestión que potencia la movilización de la inteligencia en to- 
dos los niveles, desde los auxiliares hasta los directivos. Las características esenciales de los Círculos de Calidad son:

- Grupos pequeños (con un mínimo de tres personas) con moderador pero sin presiones jerárquicas

- Acceso voluntario al grupo

- Se analizan y estudian los temas que el propio grupo decide, si bien de un modo sistemático y organizado para poder ofrecer soluciones a los problemas planteados, incluso los problemas personales

- El análisis requiere:

I. Tormenta de ideas

2. Selección de prioridades

3. Recogida de datos

4. Búsqueda de soluciones

5. Presentación de soluciones al órgano superior (comités de dirección)

6. Implantación de las soluciones aprobadas

7. Seguimiento y valoración de resultados

- Las reuniones se realizan de forma periódica, durante un tiempo limitado y retribuido

El análisis del valor ha sido implementado especialmente en grandes y medianas empresas, y se piensa que uno de los potenciales campos de aplicación es el de gestión pública, con un 50\% de tareas tratables y racionalizables con estas técnicas y un ahorro estimado de costes del 15\% por proyecto ${ }^{35}$. Sin duda, la necesidad de propuestas imaginativas y prácticas en la Gestión del Patrimonio Histórico ofrece un terreno propicio para la aplicación de estas técnicas.

\section{Evaluación Multicriterio}

Los estudios sobre las preferencias sociales y la discusión sobre la racionalidad de las decisiones individuales en ambiente de incertidumbre serán, a partir del libro de Neumann, v. J. y Morgenstern, O. (Theory of Games and Economic Behavior) de 194436, muy activos en la década de los cincuenta. Arrow, K. ${ }^{37}$, quien sería Nobel de Economía en 1972, planteó por entonces, siguiendo procedimientos de lógica matemática y ateniéndose a unos axiomas formales, su famoso Teorema de la Imposibilidad de una Función de Bienestar Social, que ponía en tela de juicio la capacidad de los regímenes democráticos para consensuar las preferencias individuales:

\section{"Si excluimos la posibilidad de hacer compara- ciones interpersonales de utilidad, entonces los únicos métodos para pasar de los gustos indi- viduales a preferencias sociales, que sean satisfactorios y que estén definidos para un amplio campo de conjuntos de ordenaciones individuales, serán impuestos o dictatoriales"}

(Arrow, K., Elección Social y Valores Individuales, 195I)
Arrow replantea la noción de índice de utilidad y la sustituye por el concepto de relación de preferencias.

Con estos y otros preceptos expuestos por distintos autores, desde la década de los sesenta comenzó a diferenciarse el Análisis Multicriterio, especialmente frente al paradigma imperante en la investigación operativa monocriterio que buscaba adoptar decisiones óptimas maximizando una función económica mediante la programación lineal.

Los nuevos planteamientos tratarían de encontrar soluciones a la elección de alternativas (posibilidades de elección) en presencia de criterios múltiples. Con este objetivo se viene formulando desde entonces una serie de métodos y refinamientos que por sus procedimientos matemáticos se distinguen en discretos - que tienen unas alternativas en un conjunto de elección que puede o no ampliarse - (ELECTRE, MAUT, Método de Jerarquías Analíticas...), y continuos - sin alternativas previas definidas - (Programación por Metas, por ejemplo).

De entre ellos cabe destacar la posibilidad de adaptar los métodos discretos para las evaluaciones y toma de decisiones sobre el Patrimonio Histórico. Convencido de esta posibilidad y creyendo que no basta con pensarlo sólo como posible sino también como realizable, a continuación se presentará una adaptación de uno de estos métodos en conjunción con la metodología de Análisis del Valor de cara a su ejecución efectiva. No obstante, creo ineludible estructurar previamente las características implícitas en el concepto de valor.

\section{DEFINICIÓN DEL CONCEPTO DE "VALOR”}

La complejidad de dar una definición comprensiva del término valor obliga a diferenciar los distintos aspectos que le dan sentido y que voy a tratar de expresar sintéticamente:

- El valor es una relación de orden establecida por un sujeto (es subjetiva) para con un objeto (es objetiva y no absoluta, como se suele confundir) y de acuerdo con uno o varios fines.

- En la relación intervienen los criterios personales derivados del conjunto social (el resto de sujetos y sus valores), y los objetos potencialmente sustitutos para la satisfacción de necesidades propias o ajenas.

- El objeto de valoración es cualquier aspecto comprensible de la realidad (objeto material, acción o hecho).

- La evaluación supone una ordenación de un conjunto de objetos en un tiempo y un espacio determinados, que se hace desde el presente con unos fines previstos y haciendo balance de resultados anteriores. Por tanto, en momentos y lugares dis- 
tintos el valor de un objeto es diferente; el valor estará siempre condicionado por la incertidumbre, aspecto que se acrecienta conforme se amplía el horizonte temporal.

- En la valoración tienen especial incidencia las experiencias más cercanas al sujeto, espacial y temporalmente.

- El orden de preferencias será mayor o menor de acuerdo, al menos, con las siguientes circunstancias:

- Adaptación del objeto de valoración a unas funciones prioritarias y otras laterales que determinan su valor.

- Escasez actual o previsible del objeto y de sus sustitutivos. En otros términos, se puede hablar de grado de rareza; de objetos "producibles" o "no producibles", "aumentables" o "no aumentables"'38.

- Cantidad e importancia de sus complementarios (por ejemplo, infraestructuras de accesibilidad).

- Eficiencia (consecución de la función con el mínimo gasto de energía, tiempo, dinero y esfuerzo) y eficacia (consecución del objetivo) ${ }^{39}$.

- Cantidad y calidad del conocimiento que el sujeto posea sobre las potencialidades del objeto y sus sustitutivos para los fines perseguidos.

- No existe ningún patrón de medida estable ni permanente, ni siquiera el dinero, la tierra o el oro; el valor es relativo por definición.

- El objeto material se convierte en bien al ser apreciado o valorado, pero no lo es de propio. Es decir, las potencialidades del objeto sólo se definen y concretan por el acto de valoración ${ }^{40}$.

Las distinciones que se han hecho entre valor de cambio, de uso, de estimación o de coste son en realidad distintos criterios en el análisis del valor. A ellos se pueden añadir otros conceptos muy utilizados en los estudios del valor como son el coste de oportunidad y el valor de opción. El coste de oportunidad ha sido definido como el coste de realizar en un mismo tiempo otra actividad alternativa ${ }^{41}$. El valor de opción, por su parte, se ha definido como la cantidad de dinero que el consumidor está dispuesto a pagar para asegurarse de que el bien continúe existiendo ${ }^{42}$. A efectos prácticos estos conceptos pueden resultar útiles en la analítica del valor, pero será conforme a cada problema de decisión como podremos determinar los mejores criterios.

\section{METODOLOGÍA DE EVALUACIÓN DEL PATRIMONIO HISTÓRICO}

La concepción de los objetos del legado histórico como bienes significa que de alguna manera son objeto de valoración (de acuerdo con los criterios de valor universal, según expuse con anterioridad). Como ya dije, la racionalización de estas valoraciones puede realizarse mediante el Análisis del Valor y la Evaluación Multicriterio de acuerdo con fines o usos patrimoniales más específicos.

El método que se propone parte de la definición inicial de unos conceptos que tienen sentido y utilidad dentro de esta estructura teórica y no tienen por qué coincidir con otras acepciones en los mismos términos; de hecho en la literatura de análisis multicriterio no existe un consenso claro en cuanto a los conceptos utilizados, e incluso algunos pueden tener el mismo significado semántico y dependiendo de cada problema pueden ser utilizados como sinóni$\operatorname{mos}^{43}$. Los conceptos necesarios para el Método de Valoración Patrimonial serán los siguientes:

- Criterios: Puntos de vista desde los cuales se procede a la valoración de la realidad analizada.

- Atributos: Cualidades o propiedades que pueden poseer los distintos bienes para el fin o fines concretos que dirigen la valoración.

- Categorías: Cada una de las opciones que materializan la presencia de un atributo. La ausencia de un atributo en un bien se considera también una categoría.

- Alternativas: Cada bien, acción o hecho que trata de ser evaluado y que puede servir al fin o fines de la evaluación. Son propuestas de elección.

Aunque se entiende que todo proceso de valoración es personal, el espíritu de consenso democrático que debe primar en las decisiones públicas obligan a forzar los mecanismos de valoración en aras de obtener la solución más satisfactoria de las posibles. Desde luego que es un objetivo ideal, utópico si se quiere, pero lo cierto es que todo fin lo es pues nunca se resuelve exactamente como deseamos todos.

Los pasos que se proponen en la toma de una decisión pública sobre Patrimonio Histórico, siempre que se pretenda consensuar, son:

I. Selección del problema o fin que se pretende alcanzar por el ente decisor más elevado, elegido democráticamente.

2. Presentación y planteamientos alternativos del problema en sesiones de Tormenta de ideas (Brainstorming): proposición y generación de ideas mediante reacción en cadena; es importante que las ideas sean anotadas y no discutidas, pues la experiencia ha demostrado que la discusión inhibe el libre flujo de las ideas; examinar y criticar instintivamente cada idea propuesta es uno de los principales obstáculos que se oponen a una reflexión creadora - otros obstáculos a evitar son: el temor al ridículo, la convicción de que las ideas "fuera de lo corriente" constituyen una pérdida de tiempo, la dificultad de aislar datos específicos, el temor a lo desconocido... Es im- 
portante realizar preguntas para estimular nuevas ideas ${ }^{44}$

3. Estudio de eficiencia y eficacia. Se examinan individualmente las alternativas y soluciones propuestas para determinar su viabilidad, debatiéndose en una nueva sesión de grupo. Se estudia la capacidad de obtener datos para la evaluación a partir de los medios disponibles y se restringen las alternativas irrelevantes.

4. La simplificación de alternativas, criterios, atributos y categorías. Este paso exige un enorme esfuerzo intelectual que se ve recompensado en la posterior recogida de datos. Es imprescindible la selección de variables lo más claramente independientes entre sí, de manera que puedan definirse y concretarse. La simplificación concreta, a su vez, los niveles jerárquicos del problema (nivel de criterios, nivel de atributos y nivel de categorías) y se reflejan en el diseño de una ficha de captación de datos.

5. Una vez recogidos los datos un procedimiento matemático (Regla de Evaluación) asigna pesos de ponderación a criterios, atributos y categorías. El valor de cada bien se obtiene por las presencias en el bien de las cualidades ideales para el fin pretendido. La regla de evaluación ha sido diseñada como una metodología de análisis multicriterio y requiere un tratamiento individualizado.

\section{La regla de evaluación}

La definición de las cualidades de una alternativa "ideal", es decir, aquella que el decisor elegiría sin dudar si pudiera, ha sido utilizada en distintos campos científicos, especialmente en la literatura psicosométrica. En el campo del análisis multicriterio se ha introducido con concepciones muy interesantes, como la "solución de compromiso" o alternativa más "próxima" al ideal, de Zeleny ${ }^{45}$, y el concepto de "punto de utopía" de Yu46; la idea es fundamental en el método de "programación por metas" de Charnes y Cooper47, donde se utiliza en la medición de distancias a una alternativa ideal. Complementariamente se encuentra en otros métodos el concepto de alternativa "anti-ideal"; tal es el caso del método TOPSIS (Technique for Order Preference by Similarity to Ideal Solution), en el que se miden distancias desde el ideal y el anti-ideal para la selección de alternativas.

En la Regla de Evaluación se propone una alternativa ideal, con unas características debatidas y consensuadas, a la cual se aproximarán más o menos las alternativas reales. Así, se ordenan relativa y numéricamente todas las alternativas reales en un rango entre cero y uno, constituyendo I el ideal y 0 el anti-ideal.

Para posicionar en este rango de valores a cada alternativa el procedimiento parte de la conformación de una estructura jerárquica parecida a la de otros modelos. Concretamente se ha tenido muy en cuenta el método AHP (Analytic Hierarchy Process) propuesto por Thomas Saaty ${ }^{48}$, del que también se ha considerado el cálculo del autovector dominante ${ }^{49}$ para la asignación de pesos a criterios y atributos, y la Razón de Consistencia para la medición de la consistencia lógica de los juicios. Sin embargo, como se verá, eso no significa que se utilicen.

Lo que sí se utiliza es la estructura jerárquica, de manera que se van asignando pesos a los elementos de cada nivel (criterios, atributos y categorías), y al final se relacionan mediante una función lineal aditiva y ponderada. Cada alternativa (bien patrimonial, o acción sobre el mismo) obtiene su valor final mediante un proceso matemático que requiere de un ejemplo práctico.

\section{Caso Práctico}

Supongamos que un Ayuntamiento desea escoger un edificio para la ubicación de unas oficinas de gestión del patrocinio cultural. Las oficinas se han concebido como un centro concertado para la divulgación y fomento del patrimonio histórico a través de actividades patrocinadas por el sector privado (exposiciones de arte contemporáneo, publicaciones, exposición de resultados de excavaciones arqueológicas...) y para su asesoramiento público (red de contactos, asistencia jurídica, acciones de voluntariado...). Para ello dispone de una serie de edificios que constituyen su conjunto de elección conforme a unos CRITERIOS que se explicitan:

\section{Imagen pública}

\section{Costes de adquisición o reformas}

\section{Utilidad funcional}

Estos requisitos máximos conforman los criterios de elección y entre ellos la corporación local establece unas preferencias. Para cuantificarlas se parte de una escala de asignación de preferencias que se establece entre I y 9; la base de esta escala es el mágico número $7 \pm 2$ de Miller ${ }^{50}$, que fija la cantidad de criterios manejables por el cerebro humano.

La PUNTUACIÓN se asigna en la escala I-9 teniendo en cuenta que las diferencias entre puntuaciones señalan la mitad, el doble, el triple... de importancia de un criterio frente a otro/s. En el ejemplo se observa como la utilidad funcional es más del doble de importante que los costes; esto no significa que no se tenga en cuenta este último criterio.

Entre los atributos el Ayuntamiento en Pleno contempla los siguientes, con sus correspondientes categorías:

Una vez determinados los atributos se procede a ponderarlos según los criterios y conforme a la escala I-9: 


\begin{tabular}{|l|c|c|}
\hline & PUNTUACIÓN & $\begin{array}{c}\text { PESO DE CRITERIO } \\
\text { (importancia relativa) }\end{array}$ \\
\hline Imagen pública & 6 & $6 / 19=0.316$ \\
\hline Costes & 4 & $4 / 19=0.210$ \\
\hline Utilidad funcional & 9 & $9 / 19=0.474$ \\
\hline & Suma $=19$ & Suma $=1$ \\
\hline
\end{tabular}

ATRIBUTOS / CATEGORÍAS

\begin{tabular}{|l|l|l|l|l|}
\hline ANTIGÜEDAD & Anterior al $\mathrm{S.XVI}$ & Moderno & Contemporáne0 & \\
\hline IITULARIDAD & Propia & Alquiler $<500 \mathrm{e}$. & Compra $<200.000 \mathrm{e}$. & Compra $>200.000 \mathrm{e}$. \\
\hline TAMAÑ̃ ADECUADO & $>1000 \mathrm{~m}^{2}$ & $>500<1000 \mathrm{~m}^{2}$ & $>300<500 \mathrm{~m}^{2}$ & $<300 \mathrm{~m}^{2}$ \\
\hline UBICACIÓN IDÓNEA & Centro histórico & Zona comercial & $\begin{array}{l}\text { Estaciones de acceso } \\
\text { (tren, autobús...) }\end{array}$ & Otros lugares \\
\hline $\begin{array}{l}\text { REFORMAS, } \\
\text { RESTAURACIÓN, } \\
\text { EXCAVACIÓN }\end{array}$ & $\begin{array}{l}\text { Financiación } \\
\text { patrocinada }\end{array}$ & F. propia $<10.000 \mathrm{e}$. & F. propia $>10.000<25.000 \mathrm{e}$. & F. propia $>25.000 \mathrm{e}$. \\
\hline
\end{tabular}

\section{CRITERIO / IMAGEN CRITERIO / COSTES CRITERIO / UTILIDAD}

\begin{tabular}{|l|c|c|c|c|c|c|}
\hline & PUNTUACIÓN & PESO ATRIBUTO & PUNT & PESO A & PUNT. & PESO A. \\
\hline Antigüedad & 9 & $9 / 21=0.429$ & 0 & 0 & 0 & 0 \\
\hline Titularidad & 0 & $0 / 21=0.000$ & 9 & 0.750 & 0 & 0 \\
\hline Tamaño & 5 & $5 / 21=0.238$ & 0 & 0 & 5 & 0.643 \\
\hline Ubicación & 7 & $\ldots=0.333$ & 0 & 0 & 9 & 0.357 \\
\hline Reformas & 0 & 0.000 & 3 & 0.250 & 0 & 0 \\
\hline
\end{tabular}

Por su parte, las CATEGORÍAS reflejan en qué porcentaje los atributos cumplen las especificaciones deseadas. Se entiende que cada atributo se manifestará mediante una y sólo una de sus categorías. Veamos, por ejemplo, el atributo antigüedad:

Para el resto de atributos se asignan también los pesos de sus correspondientes categorías, siguiendo el ejemplo anterior. Se da el caso de que algunas categorías pueden no ser deseadas (por ejemplo, las re-

\begin{tabular}{|c|c|c|c|}
\hline \multicolumn{4}{|l|}{ CATEGORÍA } \\
\hline \multicolumn{4}{|c|}{\begin{tabular}{|c|c} 
ANTIGÜEDAD & $\begin{array}{c}\text { ANTERIOR AL } \\
\text { S.XVI }\end{array}$ \\
\end{tabular}} \\
\hline categoría & $\begin{array}{l}\text { Deseado } \\
100 \%=1\end{array}$ & $\begin{array}{l}\text { Deseado } \\
90 \%=0.9\end{array}$ & $\begin{array}{c}\text { No } \\
\text { deseado }=0\end{array}$ \\
\hline
\end{tabular}

lacionadas con el coste), en cuyo caso el peso de la categoría se refleja como negativo.

\begin{tabular}{|l|c|c|c|c|}
\hline TITULARIDAD & PROPIA & $\begin{array}{c}\text { ALQUILER } \\
<500 \mathrm{e}\end{array}$ & $\begin{array}{c}\text { COMPRA } \\
<200.000 \mathrm{e} .\end{array}$ & $\begin{array}{c}\text { COMPRA } \\
>200.000 \mathrm{e} .\end{array}$ \\
\hline Pesos de categ. & $\begin{array}{c}\text { Deseado } \\
100 \%=1\end{array}$ & $\begin{array}{c}\text { No deseado } \\
-40 \%=-0.4\end{array}$ & -0.8 & -1 \\
\hline
\end{tabular}

\begin{tabular}{|l|c|c|c|c|}
\hline $\begin{array}{l}\text { TAMAÑO } \\
\text { ADECUADO } 0\end{array}$ & $\begin{array}{c}>1000 \\
\text { metros }^{2}\end{array}$ & $\begin{array}{c}>500<1000 \\
\mathrm{~m}^{2}\end{array}$ & $\begin{array}{c}>300<500 \\
\mathrm{~m}^{2}\end{array}$ & $\begin{array}{c}<300 \\
\mathrm{~m}^{2}\end{array}$ \\
\hline $\begin{array}{l}\text { Pesos de } \\
\text { categ. }\end{array}$ & 1 & 0.8 & 0.5 & 0 \\
\hline
\end{tabular}

\begin{tabular}{|l|c|c|c|c|}
\hline $\begin{array}{l}\text { UBICACIÓN } \\
\text { IDÓNEA }\end{array}$ & $\begin{array}{c}\text { CENTRO } \\
\text { HISTÓRICO }\end{array}$ & $\begin{array}{c}\text { ZONA } \\
\text { COMERCIAL }\end{array}$ & $\begin{array}{c}\text { ESTACIONES } \\
\text { DE ACCESO } \\
\text { (tren, autobús...) }\end{array}$ & $\begin{array}{c}\text { OTROS } \\
\text { LUGARES }\end{array}$ \\
\hline $\begin{array}{l}\text { Pesos de } \\
\text { categ. }\end{array}$ & 1 & 0.7 & 0.8 & 0 \\
\hline
\end{tabular}

\begin{tabular}{|l|c|c|c|c|}
\hline $\begin{array}{l}\text { REFORMAS, } \\
\text { RESTAURACIÓN, } \\
\text { EXCAVACIÓN... }\end{array}$ & $\begin{array}{l}\text { FINANCIACIÓN } \\
\text { PATROCINADA }\end{array}$ & $\begin{array}{l}\text { F. PROPIA } \\
<10.000 \mathrm{e} .\end{array}$ & $\begin{array}{c}\text { F. PROPIA } \\
>10.000<25.000 \mathrm{e} .\end{array}$ & $\begin{array}{c}\text { F. PROPIA } \\
>25.000 \mathrm{e}\end{array}$ \\
\hline Pesos de categ. & 1 & -0.4 & -0.7 & -1 \\
\hline
\end{tabular}


Finalmente para la obtención del valor de cada edificio se procede a detectar las características que se presentan en cada uno y se calcula de acuerdo con la siguiente función aditiva y ponderada:

Valor del bien $=\Sigma$ Categoría $\times$ Atributo $\times$ Criterio
Por ejemplo, un edificio del s. XVI que necesite de excavación arqueológica y reformas diversas por un coste de 20.000 euros, ubicado en el centro histórico, con un tamaño útil de $325 \mathrm{~m}^{2}$ y de titularidad municipal obtendría su valor de la siguiente manera:

\begin{tabular}{|l|c|c|c|c|}
\hline & $\begin{array}{c}\text { ATRIBUTO } \\
\text { SEGÚN IMAGEN }\end{array}$ & $\begin{array}{c}\text { ATRIBUTO } \\
\text { SEGÚN COSTE }\end{array}$ & $\begin{array}{c}\text { ATRIBUTO } \\
\text { SEGÚN UTILIDAD }\end{array}$ & $\begin{array}{c}\text { VALOR } \\
\text { POR ATRIBUTO }\end{array}$ \\
\hline Antigüedad & $(0.9 \times 0.429 \times 0.316)+$ & $(0.9 \times 0 \times 0.210)+$ & $(0.9 \times 0 \times 0.474)$ & $=0.284$ \\
\hline Titularidad & $(1 \times 0 \times 0.316)+$ & $(1 \times 0.75 \times 0.210)+$ & $(1 \times 0 \times 0.474)$ & $=0.118$ \\
\hline Tamaño & $(0.5 \times 0.238 \times 0.316)+$ & $(0.5 \times 0 \times 0.210)+$ & $(0.5 \times 0.643 \times 0.474)$ & $=0.191$ \\
\hline Ubicación & $(1 \times 0.333 \times 0.316)+$ & $(1 \times 0 \times 0.210)+$ & $(1 \times 0.357 \times 0.474)$ & $=0.274$ \\
\hline Reformas en edificio & $(-0.7 \times 0 \times 0.316)+$ & $(-0.7 \times 0.25 \times 0.210)+$ & $(-0.7 \times 0 \times 0.474)$ & $=-0.037$ \\
\hline \multicolumn{4}{l|}{ VALOR DEL EDIFICIO (en escala relativa de $0 \mathrm{a} 1)$} & 0.830 \\
\hline
\end{tabular}

Este edificio ha obtenido una puntuación alta con respecto al ideal y el anti-ideal pero tendrá que recurrirse a la valoración de todos los bienes disponibles para concretar su valor con respecto a sus sustitutivos. Por ejemplo, un edificio del s. XV, de titularidad municipal, con tamaño superior a los 1.000 metros cuadrados, ubicado en el centro histórico y sin necesidad de reformas obtendría valor óptimo $(=1)$. Por contra, un edificio de los años ochenta, con precio de 250.000 euros, con tamaño inferior a los 300 metros cuadrados, ubicado en un suburbio y con coste de reformas superior a 25.000 euros obtendría un valor negativo (-0.210) lo que sería equivalente a valor pésimo $(=0)$.

Evidentemente, este caso práctico no aglutina todos los criterios, atributos y categorías que entrarían en consideración en un caso real de esta índole; con él solo se ha pretendido hacer comprensible la Regla de Evaluación. En un caso real la conceptualización de la estructura jerárquica exigiría gran parte de la reflexión, de ahí la necesidad de consenso en las fases previas.

En ocasiones resulta ventajoso o necesario establecer criterios como clases excluyentes (por ejemplo, los criterios de la UNESCO de Monumento/Conjunto Histórico/Lugar Histórico); en tales casos la alternativa ideal pertenecerá al criterio/clase mejor considerado. El procedimiento matemático sufrirá una leve modificación, consistente en la normalización de los valores de las alternativas reales en el rango cero-uno: para ello se divide el valor obtenido para las alternativas reales, por el peso de ponderación del criterio/clase mejor considerado. El resultado supone una aproximación a la evaluación monocriterio, que a veces es imprescindible.

Como se ha podido observar, en la Regla de Evaluación la asignación de pesos a criterios y atributos se realiza mediante el cálculo de frecuencias relativas a partir de las puntuaciones. El procedimiento es equivalente al cálculo del autovector dominante con razón de consistencia perfecta (R.c. $=0$ ) que proporcionaría el método AHP.

Las ventajas más sobresalientes de la Regla de Evaluación son el fácil relleno de fichas que requiere, su gestión adecuada en bases de datos, su implementación óptima en los denominados Sistemas de Información Geográfica para la relación de variables territoriales y, sobre todo, su versátil aplicabilidad a multitud de circunstancias. A ello hay que añadir que no muestra ningún reparo en hacer explícitas las puntuaciones de criterios y atributos, imprescindible para la recepción de críticas constructivas. Entre sus handicaps se encuentra el enorme esfuerzo intelectual en la concreción de conceptos y puntuaciones, y el requerimiento de información de las mejores fuentes.

\section{HACIA UNA GESTIÓN ESTRATÉGICA DEL PATRIMONIO HISTÓRICO}

El Método de Valoración Patrimonial trata de ofrecerse como una herramienta operativa para el diagnóstico estratégico propio de todo proceso de planificación. No es, ni mucho menos, un sustituto del sistema de valores por una sistema adhocrático en el que los problemas se resuelven ad hoc en el momento de presentarse. Si bien puede ser resolutivo en cuestiones decisorias puntuales, lo cierto es que el método ha sido diseñado como un instrumento integrado para la planificación y la gestión estratégica. Podemos definir aquí la planificación patrimonial como un proceso basado en la investigación y la evaluación que incluye la identificación de problemas, la formulación de alternativas y la asignación de los recursos patrimoniales a fines diversos; evidentemente, cuanto mayor sea el plazo temporal mayor incertidumbre existirá en la obtención de resultados.

La metodología es especialmente apta para aquellos órganos e instituciones consultivas del patrimonio histórico que deben mediar en conflictos entre dis- 
tintas actitudes, unas más sensibles al valor estético, otras a su función pedagógica, otras a sus funciones turísticas y de desarrollo sostenible... La necesidad de establecer principios para dirimir las alternativas que surjan en torno al patrimonio ha sido expresada en distintos momentos; citaré tan sólo dos casos de especial relevancia.

El primero se refiere a las peticiones del Patronato Europeo a la Comisión Europea sobre la conservación del patrimonio arquitectónico y arqueológico51. Entre otras cuestiones se pide a la Comisión que

\begin{abstract}
"encargue al Instituto para los Bienes Culturales, Artísticos y Naturales de Bolonia y al Centro para la Conservación del Patrimonio de Lovaina que procedan a una observación permanente de la evolución de la rentabilidad económica y social de la conservación en los países de la Comunidad..."
\end{abstract}

"encargue a estos mismos Institutos o a otros órganos expertos, como el York Institute for Advanced Architectural Studies y el Centro Universitario Europeo para los Bienes Culturales de Ravello, la función de establecer los principios para dirimir las alternativas que surjan en torno a la Preservación o eventual Reconstrucción y reutilización de los edificios, su Aislamiento para la investigación o su Accesibilidad al público, etc."

"fomente asimismo la evaluación de las alternativas que las ciudades europeas han tomado para preservar las construcciones de sus centros históricos: terciarización, gentrificación, reutilización municipal, etc."

El segundo caso se encuentra en la comparencia de la ex-ministra Esperanza Aguirre ante la Comisión de Educación y Cultura del Congreso para explicar la política general en materia de Cultura a solicitud del Grupo Parlamentario Socialista ( 8 de diciembre de (996) ${ }^{52}$. Refiriéndose a las actividades del Instituto de Patrimonio Histórico Español (antes llamado Instituto de Conservación y Restauración de Bienes Culturales), señalaba la realización de un estudio de evaluación de sus actuaciones para establecer prioridades y disminuir costes superfluos; en esta línea el Instituto procedería a definir un catálogo nacional de actuaciones basándose en un doble criterio: actuación en inmuebles desatendidos y actuación como centro de investigación. El objetivo lo establecía en dar eficacia y coherencia a una política de actuaciones del Instituto que hasta entonces consideraba dispersa e incluso arbitraria en ocasiones. Aunque desconozco los resultados de aquellos estudios, lo cierto es que manifiestan la necesidad de priorizar actuaciones, lo cual no es limitativo del partido en el gobierno: en Andalucía el partido socialista insiste en esta necesidad en el Avance del nuevo Plan General de Bienes Culturales (1996-2000) ${ }^{53}$ cuando se plantea racionalizar las prioridades de inversión y mejorar la gestión y la calidad de las intervenciones sobre el patrimonio histórico.

Aunque una metodología de racionalización explícita de criterios y atributos como la que ha sido planteada puede aplicarse por las instituciones consultivas de la UNESCO ${ }^{54}$, de la Administración del Estado55 y de las Comunidades Autónomas ${ }^{56}$ en las consultas puntuales que reciben, en realidad donde puede ser más importante su contribución es en la gestión de sistemas de información patrimonial. La necesidad de hacer relaciones entre multitud de variables que afectan al patrimonio y la posibilidad de utilizar herramientas informáticas incrementa enormemente las potencialidades de la Metodología de Valoración Patrimonial. Concretamente es posible la implementación de técnicas de análisis multicriterio en Sistemas de Información Geográfica y, de hecho, la Administración Andaluza ha apostado por su ensayo en estudios de riesgo arqueológico ${ }^{57}$. En este sentido, es de resaltar su potencialidad en los Estudios de Impacto Ambiental y en los Planes de Ordenación del Territorio, tanto a escala regional como urbana. De hecho, la metodología aquí expuesta, con leves diferencias, ha servido para estudios de valoración del potencial informativo de las intervenciones arqueológicas urbanas ${ }^{58}$. Al capacitar la relación espacio-temporal de los bienes, una prestación importantísima y de inmediata aplicación se encuentra en la gestión de inventarios: la definición de las funciones y realidades más usuales y cercanas al patrimonio y sus usuarios sería necesaria de cara al diseño de bases de datos válidas para la valoración en situaciones diversas. La metodología puede utilizarse también para el análisis DAFO (identificación de puntos Fuertes y Débiles y determinación de Amenazas y Oportunidades) de recursos turísticos, para la formulación estrategias y selección de procedimientos 59 .

La experiencia acumulada por el personal de la administración es esencial en el análisis del valor, aunque no la única (sector privado, entidades municipales...). Para su aprovechamiento la consulta pública resulta apropiada y ha sido ensayada en algún caso ejemplar, como en la experiencia iniciada por el Museo de Bellas Artes de Vitoria, que en 1987 comenzó a enviar formularios a los artistas con preguntas y opciones sobre el uso de técnicas y materiales, para perfeccionar así los criterios de restauración de las obras; en 1993 la base datos, gestionada ya por otras entidades de mayor amplitud territorial (diputaciones forales), alcanzaba a más de 200 artistas encuestados ${ }^{60}$. He de indicar en este sentido que la versatilidad de los procedimientos propuestos los capacita para el estudio de patologías, factores de deterioro y estados de conservación de todo tipo de bienes de cara al diagnóstico de intervenciones de restauración en situaciones de conflicto de criterios; no obstante, la tradición técnica en este campo quizá puede proporcionar cauces resolutivos más adecuados.

Un aspecto que a menudo se elude y que es importante destacar es la clarificación de criterios en la 
asignación de recursos económicos y tasaciones sobre los bienes, función que en el ámbito nacional corresponde a la Junta de Calificación, Valoración y Exportación de Bienes del Patrimonio Histórico Españo|61. La valoración monetaria de bienes privados que la Administración, o en su caso las comisiones académicas pertinentes, está obligada a ejercer y justificar en determinadas circunstancias puede indicarse como una aplicación precisa del método; podemos señalar las siguientes circunstancias genéricas que obligan a la tasación de los bienes:

I. Las compensaciones económicas al propietario y al descubridor de bienes muebles en un $50 \%$ del valor del bien62, fijado por informe pericial de conformidad con la Ley de expropiación forzosa ${ }^{63}$.

Un caso muy llamativo y de especial trascendencia en la redacción de la actual legislación patrimonial fue el del sonado litigio de la Dama de Baza; después de consumirse las tres instancias judiciales (la Audiencia modificó el fallo del Juzgado, y el Tribunal Supremo el de la Audiencia64) el proceso concluyó con la tasación de la Dama, primero por resolución de 4 de febrero de 1977, de la Dirección General del Patrimonio Artístico y Cultural, que fijó el justoprecio de la Dama en 450.000 pts. 65 (ateniéndose al precio de adquisición de la Dama de Elche por el Museo del Louvre en I897); y después, tras el recurso del propietario, en la "sumamente prudente" cantidad de treinta millones de pesetas establecida por Fernando Chueca Goitia y aceptada por sentencia de 1987, basándose en las características de la escultura, su pintura, los detalles del traje y tocado y su condición de urna funeraria66.

2. La valoración de bienes culturales para la imposición de tasas mínimas a la exportación fuera de la Comunidad Europea ${ }^{67}$.

3. La determinación de los valores mínimos aplicables como indemnización eventual que acompaña a la restitución de un bien salido de forma ilegal de algún Estado de la Unión Europea68.

El mecanismo por el que se fijan estos mínimos podemos observarlo en la ley de modificación parcial de la ley69.

"La experiencia pone de manifiesto que los precios de los cuadros realizados con acuarelas, aguadas y pasteles son más elevados que los de los dibujos, pero claramente inferiores a los de las pinturas al óleo o al temple, por 10 que conviene clasificar los cuadros realizados con acuarelas aguadas y pasteles en una nueva categoría distinta con un valor mínimo de 30.000 ecus, con lo que se garantizaría que las obras más importantes que hayan salido de forma ilegal del territorio de un Estado miembro puedan restituirse".

(Ley de modificación parcial de la Ley 36/1994)
4. Las valoraciones necesarias para el pago de deudas tributarias mediante entrega de bienes del $\mathrm{Pa}$ trimonio Histórico Españo|70, o de bienes del Patrimonio Histórico Andaluz ${ }^{71}$ para satisfacer deudas con la Junta de Andalucía.

5. La elección de bienes dignos de ejercer sobre ellos el derecho de tanteo por parte de la Administración Estatal72 $\circ$ Autonómica 73 .

6. En Andalucía también se requiere de tasación del valor de aquellos bienes inscritos en el Catálogo General que hayan recibido orden de ejecución de obras de restauración por los órganos competentes de la Consejería de Cultura ${ }^{74}$.

7. La suscripción de póliza de seguro por préstamo para exposiciones temporales de bienes de museos ${ }^{75}$.

Para conocer y normalizar precios con la realidad del mercado pueden resultar útiles los libros de registro de transmisiones comerciales propuestos en la Convención de la UNESCO en París (1970) y asumidos en nuestra legislación76, así como las valoraciones que los particulares realizan en las notificaciones de transmisión de bienes ${ }^{77}$ y en las solicitudes de exportación ${ }^{78}$; y todo ello comparado con las circunstancias socioeconómicas coyunturales.

Sin ánimo de extender un catálogo de aplicaciones de la metodología, quisiera terminar recuperando la reflexión sobre los valores como colofón a este largo texto. En mi opinión, los valores sociales pertenecen al inconsciente colectivo y encuentran en la Historia y más concretamente en su referente material, el $\mathrm{Pa}$ trimonio, una correa de transmisión de los mismos a las generaciones futuras. El papel endoculturador de la Historia es claro en la enseñanza reglada; su papel se ha justificado en los siguientes aspectos ${ }^{79}$.

- Comprensión de la naturaleza humana y de la realidad social actual.

- Conocimiento crítico de la herencia personal y colectiva para así comprender, y no necesariamente compartir, las actitudes, los valores y memorias propias de la Comunidad.

- Materia especialmente indicada para enseñar que el conocimiento científico es antidogmático, provisional y discutible.

- Comprensión de las sociedades como productos contingentes.

- Enriquecimiento de nuestras limitadas experiencias personales.

- Utilización práctica de las fuentes documentales.

Este papel educativo traspasa las aulas y trata de ejercitarse en la difusión del Patrimonio, respetando las expectativas del ciudadano, despertándolas y manipulándolas cuando es posible. La educación cívica inte- 
gra en los grupos sociales unos valores o prejuicios que al estar sancionados socialmente sirven de referencia para enjuiciar. En realidad los valores se corresponden con los criterios de valoración, con lo que la paradoja está servida: si los valores son criterios de valoración ¿qué es lo que se valora del Patrimonio Histórico?. Tradicionalmente los valores son aceptados como intrínsecos e invariables en los bienes del Patrimonio Histórico, cuando en realidad se modifican con las modas y cambios socioeconómicos; el atentado contra los valores de estos bienes, el expolio, se san- ciona legalmente pero al resultar fundamentado en intangibles la normativa se convierte en inoperante. La opción es documentar los usos y sus modificaciones de forma que los bienes puedan ser estimados, valorados en función de los distintos criterios (valores) y sus daños determinados por el impedimento de funciones que el expolio provoca. Mi conclusión es que lo que se valoran son las funciones o usos que cumple el bien y que hay que centrar en ellos las figuras de protección contra el daño, las medidas de fomento y de gestión del Patrimonio.
| Cicerón, La Invención Retórica. Ed Gredos. Madrid, 1997. Introducción, Traducción y Notas de Salvador Núñez.

2. Urrutia, J., Sistemas de Comunicación. Serie Semiótica y Crítica, Ed. Alfar. Sevilla, 1990.

3. Trigger, B. G., Historia del Pensamiento Arqueológico, Ed. Crítica. Barcelona, 1992. Traducción del original: A History of Archaeological Thougth. Cambridge University Press, Cambridge, 1989

4. Woolley,C.L., Ur of the Chaldess, Penguin.Harmondsworth, 1950 (I ${ }^{\text {a }}$ ed., 1929); citado en Trigger (1992)

5. Weiss, R., The Renaissance Discovery of Clasical Antiquity, Basil Blackwell,Oxford, 1969; citado en Trigger (1992)

6. Alvarez,.J.., Estudios sobre el Patrimonio Histórico Español y la Ley de 25 de Junio de 1985. Ed. Civitas. Madrid, 1989. Véase también: García de Enterría, E., " Consideraciones sobre una nueva legislación del patrimonio artístico, histórico y cultural". Revista Española de Derecho Administrativo, 36, pp. 575-591. Madrid, 1993

7. Modificaciones introducidas en el Documento Constitutivo de la Organización de las Naciones Unidas para la Educación, la Ciencia y la Cultura (publicado en BOE de II de mayo de 1982) desde 1982 en las sucesivas reuniones de la Conferencia General de la Organización. (BOE núm 300, de 16 de diciembre de 1994)

8. BOE núm I56, de I de julio de 1982

9. Algunas Conferencias de la UNESCO lo manifiestan públicamente, como la de Londres de 1969 y la de Laussanne de 1990.

10. Ley 16/1985, de25 de junio, de Patrimonio Histórico Español (BOE núm. 155, de 29 de junio; corrección de errores en BOE núm. 296, de II de diciembre)

11. Convención de 3 de noviembre de 1972, de Protección del Patrimonio Mundial Cultural y Natural (BOE núm 156, de I de julio de 1982)

12. página web de la UNESCO (http://www.unesco.org).

13. Ley |/|99|, de 3 de julio, de Patrimonio Histórico de Andalucía (BOJA núm. 59, de 13 de julio)

14. En la normativa andaluza la "Instrucción I/93, de 20 de julio, de la Dirección general de Bienes Culturales, por la que se establecen criterios para la selección del carácter de la inscripción de bienes en el Catálogo General del Patrimonio Histórico Andaluz" hace una pobre aportación (no nula, pero sí insuficiente) en la delimitación de estos conceptos universalistas.

I5. Dorado, P., Valor Social de Leyes y Autoridades. Ed. Calpe. Barcelona, 1923.

16. Sancho, A. "El Patrimonio Histórico de la Iglesia", Razón y Fe, mayo de 1984; citado en Alvarez,.J.L. (1989)
17. "Acuerdo entre el Estado Español y la Santa Sede sobre Enseñanza y Asuntos Religiosos, firmado en la Ciudad del Vaticano el 3 de enero de 1979, ratificado por Instrumento de 4 de diciembre de 1979 " (BOE núm.300, de 15 de diciembre; corrección de errores en BOE núm. 44, de 20 de febrero de 1980)

18. Ayuntamiento de Sevilla, Gerencia de Urbanismo. El Conjunto Histórico de Sevilla. Avance del Plan Especial de Protección. Ed. Ayuntamiento de Sevilla. 1995.

19. Franch, J. J., Fundamentos del Valor Económico; Unión Editorial. Madrid, 1990.

20. Smith, A., Investigación sobre la Naturaleza y Causas de la Riqueza de las Naciones. Fondo de Cultura Económica; México, 1982. Citado en Franch, J. J. (1990)

21. Ricardo, D., Principios de Economía Política y Tributación; Ed. Ayuso. Madrid, 1973. Citado en Franch, J. J. (1990)

22. Marx, K., El Capital. Crítica de Economía Política. Ed. Siglo XXI, $2^{a}$ Edición. Madrid, 1975. Citado en Franch, J. J. (1990)

23. Barbè, L., De la Doctrina Clásica del Valor. Antoni Bosch, editor; Pretextos. Barcelona, 1986.

24. Bentham, Principios de Ética y Legislación. 1780. Citado en Barbè (1986). Propuesta: "los placeres y la evitación de las penas son fines cuyo valor podemos comprender... éste será mayor o menor de acuerdo con siete circunstancias: I. Su intensidad. 2. Su duración. 3. Su certidumbre o incertidumbre. 4. Su proximidad o lejanía 5. Su fecundidad 6. Su pureza. 7. Su extensión"

25. Menger, C, Principios de Economía Política; Unión Editorial. Madrid, 1985. Citado en Franch, J. J. (1990). $2^{\text {a }}$ edición de 1997.

26. Walras, L., Elementos de Economía Política Pura; Alianza Editorial, Madrid, 1987. Citado en Franch, J. J. (1990)

27. Pareto, V., Cours d'économie politique, 1896. Citado en BarbaRomero, S. y Pomerol, J-C. (1997).

28. Barba-Romero, S. y Pomerol, J-C., Decisiones Multicriterio. Fundamentos Teóricos y Utilización Práctica. Universidad de Alcalá, 1997.

29. Mas-Colell, "Introducción" a Arrow, K. Elección Social y Valores Individuales, Instituto de Estudios Fiscales; Ministerio de Hacienda. Madrid, 1974.

30. Bergson, A., "A reformulation of certain aspects of Welfare economics". Quaterly Journal of Economics, 52, 1938. Citado en Arrow, K. (1974).

31. Gonzalo, J. y M. A. Luque, Introducción al Análisis del Valor. Instituto Andaluz de Tecnología; Servicio de Reindustrialización y Promoción Industrial; Junta de Andalucía. Sevilla, 1992.

32. Miles, L. D., Análisis del Valor. Ed, Deusto. Bilbao, 1970. 
33. Sobre Brainstorming, en Miles, L. D. (1970) se citan: • "New Ways to Find New Ideas". Time, 18 Feb., 1957. - Clark, C., Brainstorming. Doubleday \& Company, Inc. New York, 1958.

34. Gonzalo, J. y M. A. Luque (1992)

35. Gonzalo, J. y M. A. Luque (1992)

36. Neumann, v. J. y Morgenstern, O., Theory of Games and Economic Behavior. Princeton University Press, 1944.

37. Arrow, K. Elección Social y Valores Individuales, Instituto de Estudios Fiscales; Ministerio de Hacienda. Madrid, 1974 (traducción del original: Social Choice and Individual Values. Willey, New York, 1951.)

38. Kaldor, N., Ensayos sobre el valor y la distribución. Ed Tecnos. Madrid, 1973 (traducción del original: Essays on Value and Distribution; 1960). En esta obra, poco recomendable para lectores impacientes, Kaldor nos ofrece la distinción que he hecho: "Incluso si la distinción entre recursos "permanentes" y "no permanentes" o entre recursos "originales" y "producidos" es insostenible o irrelevante, puede establecerse una distinción entre recursos "producibles" y "no producibles" (o más bien, "aumentables" o "no aumentables".

39. Bennet, D., Evaluación de un Programa de Educación Ambiental. Guía práctica para el profesor. Programa Internacional de Educación Ambiental. UNESCO-PNUMA. Ed. Los Libros de la Catarata. Bilbao, 1993 (traducción del original: Evaluating Environmental Education in Schools. UNESCO, 1993).

40. En este sentido C. Barrero señala que jurídicamente "Bien Cultural es pues no aquel que presenta un interés de esta naturaleza, sino el que presentándolo ha sido expresamente declarado como tal" (Barrero, C., "Los Conjuntos históricos y el planeamiento de protección. Especial referencia a la Comunidad Autónoma de Andalucía". Revista Andaluza de Administración Pública. Núm. 16. Sevilla, 1993)

La importante discusión que se presenta es si este acto administrativo tiene naturaleza declarativa o constitutiva, aspecto éste de importantes implicaciones en la comprensión de la ley y que podemos encontrar desarrollado en la obra de: Alonso lbáñez, Ma del Rosario, El Patrimonio Histórico. Destino Público y Valor Cultural. Servicio de Publicaciones de la Facultad de Derecho de la Universidad de Oviedo. Ed. Cívitas. Madrid, 1992.

4I. Franch, J. J. (1990);

42. Johansson, P-O, "Diferentes Contextos en la Valoración Ambiental" en: Ferreiro Chao, A., Azqueta Oyarzun, D. y otros, Evaluación Económica de los Costes y Beneficios de la Mejora Ambiental. Ed. Consejería de Cultura y

Medioambiente. Agencia de Medioambiente. Camas (Sevilla), 1992.

43. Romero, C., Teoría de la Decisión Multicriterio: Conceptos, Teorías y Aplicaciones. Alianza Editorial. Madrid, 1993.

44. Gonzalo, J. y M. A. Luque (1992).

45. Zeleny, M., Multiple criteria decision making. McGrawHill. New-York, 1982. Citado en Barba-Romero, S. y Pomerol, JC. (1997).

46. Yu, P.L., "A class of solutions for group decision problems", Management Science, vol. 19, n 8, p. 936-946. 1973. Citado en Barba-Romero, S. y Pomerol, J-C. (1997).

47. Charnes, A. Y Cooper, W., Management Models and Industrial Applications of Linear Programming. John Wiley and Sons. 1961. Citado en Barba-Romero, S. y Pomerol, J-C. (1997)

48. - Saaty, T., "A scaling method for priorities in hierarchical structures", Journal of Mathematical Psychology, vol. 15, n 3, p.234-28I. 1977. Citado en Barba-Romero, S. y Pomerol, JC. (1997).

- Saaty, T. The Analytic Hierarchy Process, McGrawHill, 1980. - Saaty, T. Decision Making for Leaders: The Analytic Hierarchy Process for Decisions in a Complex World, RSW Publications, 3'd edition. Pittsburgh, USA. 1995.

Citados en Barba-Romero, S. y Pomerol, J-C. (1997).

49. Hay que decir que fue propuesto inicialmente en el método DARE de Klee a principios de los 70: Klee, A.J., "The role of decision models in the evaluation of competing environmental health alternatives", Management Science, vol. I8, n²,p. B52-B67. 197I. Citado en Barba-Romero, S. y Pomerol, J-C. (1997).

50. Miller G. A., "The magical number seven plus or minus two: Some limits on our capacity for processing information". Pychological Review, vol. 63., p8I-97. 1956. Citado en BarbaRomero, S. y Pomerol, J-C. (1997).

51. Resolución de 28 de octubre de 1988, del Patronato Europeo, sobre la Conservación del Patrimonio Arquitectónico y Arqueológico de la Comunidad Europea (DOCE n C 309/423-427)

52. Boletín Oficial de las Cortes Generales. Congreso de los Diputados. VI Legislatura. Serie A. Comisión de Educación y Cultura, 18 de diciembre de 1996. Núm. 126. Comparecencia de la Sra. Ministra de Educación y Cultura (Aguirre y Gil de Biedma) para explicar la política general en materia de Cultura a solicitud del Grupo Parlamentario Socialista (Número de expediente 213/000060).

53. Plan General de Bienes Culturales 1996-2000. Documento de Avance. Enero, 1997. Junta de Andalucía. Consejería de Cultura.

54. Véase también: Acuerdo de 9 de junio de 1998, del Consejo de Gobierno, por el que se aprueba el Plan General de Bienes Culturales y su remisión al Parlamento (BOJA núm. 81 de 21 de julio de 1998)

La Convención de 3 de noviembre de 1972, de Protección del Patrimonio Mundial Cultural y Natural (BOE núm I56, de I de julio de 1982) señala en su art. 8.3. como órganos consultivos del Comité: el Centro Internacional de estudios para la Conservación y Restauración de los Bienes Culturales (Centro de Roma), el Consejo Internacional de Monumentos y Lugares de Interés Artístico e Histórico (ICOMOS), La Unión Internacional para la Conservación de la Naturaleza y sus Recursos (UICN) y otras organizaciones con objetivos similares y a petición de los Estados Partes.

55. El art. 3.2. de la Ley 16/1985 de Patrimonio Histórico Español expresa que, sin perjuicio de las funciones atribuidas al Consejo del Patrimonio Histórico, son instituciones consultivas de la Administración del Estado la Junta de Calificación, Valoración y Exportación de Bienes del Patrimonio Histórico Español, las Reales Academias, las Universidades Españolas, El Consejo Superior de Investigaciones Científicas y las Juntas Superiores que la Administración del Estado determine por vía reglamentaria, y en lo que pueda afectar a una Comunidad Autónoma, las Instituciones por ella reconocidas.

El art. 10 del R.D. 1 | |/1986, de 10 de enero, por el que se desarrolla parcialmente la Ley 16/1985, de 25 de junio de 1985, de Patrimonio Histórico Español señala también como instituciones consultivas a:

a) La Junta Superior de Monumentos y Conjuntos Históricos.

b) La Junta Superior de Archivos.

c) El Consejo Coordinador de Bibliotecas.

d) La Junta Superior de Arte Rupestre.

e) La Junta Superior de Museos.

f) La Junta Superior de Excavaciones y Exploraciones Arqueológicas.

g) La Junta Superior de Etnología.

56. La Ley |/|99| de Patrimonio histórico de Andalucía señala (art. 108) como órganos consultivos de la Comunidad Autónoma a los efectos del art. 3.2 de la Ley 16/1985, el Consejo Andaluz del Patrimonio Histórico, las Comisiones Andaluzas de Bienes Culturales, y las Comisiones Provinciales de Patrimonio Histórico.

57. Amores, F.; Márquez H.; Pérez Quesada, P.: Mapa Arqueológico de Riesgo de la Comunidad Autónoma de 
Andalucía. Análisis Exploratorio, 1998. Servicio de Protección del Patrimonio Histórico. Dirección General de Bienes Culturales, Consejería de Cultura; Junta de Andalucía. Documento Interno. Sevilla, 1998.

El ensayo ha servido de avance para un estudio de mayor profundidad teórica:

Márquez Rosales, H., El Riesgo Arqueológico en Andalucía: una evaluación a partir del método de jerarquías analíticas de T. L. Saaty y los sistemas de información geográfica. Documento de Tesina. Sevilla, 1999.

58. Amores, Fi; González,D.; Pavón, l.; Pérez Quesada, P.: "La Evaluación del Potencial Informativo de las Intervenciones Arqueológicas en los Yacimientos Urbanos: Aplicación del Modelo para la Ciudad de Sevilla" Actas del XXV Congreso Nacional de Arqueología. Valencia, 1999.

59. Crosby, A. ; Moreda, A., Desarrollo y Gestión del Turismo en Areas Rurales y Naturales. Centro Europeo de Formación Ambiental y Turística. Madrid, 1996.

60. Ruiz Arcaute, E.: "Base de datos sobre las técnicas de los artistas contemporáneos y sus criterios en materia de conservación y restauración". Boletín del Instituto Andaluz del Patrimonio Histórico. № 3. pp. 5-6. Sevilla, Junio, 1993,

6I. Capítulo II; Arts. 7-9, del R.D. I I I/1986, de 10 de enero.

62. Decreto 19/1995, de 7 de febrero, por el que se aprueba el Reglamento de Protección y Fomento del Patrimonio Histórico de Andalucía (BOJA núm. 43, de 17 de marzo). Art.79. Derechos de los descubridores.

63. Ley de Expropiación Forzosa, de 16 de diciembre de 1954 (BOE núm. 35 I de 17 de diciembre) y Reglamento que la desarrolla, aprobado por Decreto de 26 de abril de 1957 (BOE núm. 160, de 20 de junio).

64. Alvarez, J.L., "La Dama de Baza. Comentario a la Sentencia del Tribunal Supremo de 22 de marzo de 1976". Revista de Derecho Privado. Tomo LX, pp. 569-597. Enero-Diciembre, Madrid, 1976.

Véase también: ARANZADI, Repertorio de Jurisprudencia 1976, pp. I058-1060. "S. 22 marzo 1976. Civil. Tesoro oculto: en finca arrendada, descubrimiento no por casualidad; Patrimonio Artístico Nacional".

65. ARANZADI, Repertorio de Jurisprudencia 1983, pp. 929931. "S. 4 marzo 1983. CONT. -ADM. (Sala 5a).

Expropiación forzosa: justiprecio: hallazgo arqueológico: nor mativa aplicable; tasación en vía administrativa de: cuya propiedad y participación en el precio han sido fijados en sentencia firme en vía jurisdiccional civil: procedencia; necesidad de motivar acuerdos valorativos. Competencia. "La Dama de Baza".

66. ARANZADI, Repertorio de Jurisprudencia 1987, pp. 501 502. "S. 10 febrero 1987. CONT.-ADM. (Sala 5ª). Expropiación Forzosa: justiprecio de pieza arqueológica: criterios estimativos: "Dama de Baza"

67. Reglamento (CEE) n 3911/92 del Consejo, de 9 de diciembre de 1992 relativo a la exportación de bienes culturales (DOCE núm. L 74/80, de 27 de marzo de 1993). Reglamento (CEE) n 752/93 de la Comisión, de 30 de marzo de 1993, relativo a las disposiciones de aplicación de Reglamento (CEE) $n^{\circ} 3911 / 92$ del Consejo relativo a la exportación de bienes culturales (DOCE núm. L 77/24, de 31 de marzo).
68. Ley 36/1994, de 23 de diciembre, Incorporación al ordenamiento jurídico español de la Directiva 93/7/CCE del Consejo, de 15 de marzo, relativa a la restitución de bienes culturales que hayan salido de forma ilegal del territorio de un estado miembro de la Unión Europea.

69. Ley 18/1998, de 15 de junio, de modificación parcial de la Ley 36/1994, de 23 de diciembre, relativa a la restitución de bienes culturales que hayan salido de forma ilegal del territorio de un estado miembro de la Unión Europea. (BOE núm. 143, de 16 de junio de 1998)

70. Art. 73 de la Ley 16/1985 de PHE.

71. Art. 90 de la Ley 1//99/ de PHA.

72. Art. 38 de la Ley 16/1985 de PHE.

73. Art. I 8 de la Ley $1 / 199 \mid$ de PHA. Se desarrolla en Arts. 28 y 29 del Decreto 19/1995.

74. Art. I6. de la Ley I/I99| de PHA. Se desarrolla en Arts. 26 y 27 del Decreto 19/1995.

75. Art. 16.d) del Decreto 284/1995, de 28 de noviembre, por el que se aprueba el Reglamento de Creación de Museos y de Gestión de Fondos Museísticos de la Comunidad Autónoma de Andalucía(BOJA núm. 5, de 16 de Enero).

76. Instrumento de ratificación de la Convención sobre las medidas que deben adoptarse para prohibir e impedir la importación, la exportación y la transferencia de propiedad ilícitas de bienes culturales, hecha en París el 17 de noviembre de 1970 (BOE núm. 31, de 5 de febrero de 1986). Su articulación en la ley 16/1985 de PHE se encuentra en el Art. 26.4 y desarrollado en el Art. 27 de su Reglamento (Decreto I I I/ /986); en Andalucía se encuentra en el Art. 46 de la ley |/199| y en los Arts. 68 a 7/ del Decreto $19 / 1995$.

77. Art. 38.I de la Ley 16/1985 de PHE y Arts. 40.1 y 40.2 de su Reglamento (Decreto I I |/ |986) para el ámbito nacional; y para el autonómico los Arts. 18.2 y 18.5 de la Ley |/|99| de PHA, Art. 28.2 del Decreto 19/1995 y 6.6 del Decreto 4/1993, de 26 de Enero, por el que se aprueba el Reglamento de Organización Administrativa del Patrimonio Histórico de Andalucía.

78. Art. 30.d) de la Ley 16/1985 de PHE y Art. 46. Ic) de su Reglamento (Decreto I I |/|986). El modelo del formulario de exportación en que debe figurar el valor del bien se encuentra publicado en el Anexo del Reglamento (CEE) $n^{\circ}$ $752 / 93$.

79. Domínguez, J., "El lugar de la Historia en el currículum I I - 6. Un marco general de referencia". En: Carretero, M.; Pozo, J.l.; Asencio, M. La Enseñanza de las Ciencias Sociales. pp.35-43 Ed. Visor. 1989. 